\title{
37
}

\section{Peripheral Nerve Injuries}

\author{
Maria Siemionow and Erhan Sonmez
}

There are different types of peripheral nerve problems that include nerve trauma, compression, tumors, and so on, and repair of peripheral nerve injuries continues to be a major challenge in reconstructive surgery. Satisfactory functional recovery after a peripheral nerve injury is dependent on accurate regeneration of axons to the original end organs. Reconstruction of peripheral nerve injuries has improved particularly over the last two decades with the experience in traumatic nerve injuries gained particularly during wartimes. In this chapter, we review different types of peripheral nerve injury problems including neuropathies, nerve repair techniques, clinical outcomes, and future strategies.

\section{Abbreviations}

CTS Carpal tunnel syndrome

NSAIDs Nonsteroidal anti-inflammatory drugs

NGF Nerve growth factor

\section{Introduction}

Peripheral nerve injuries may result in devastating outcome, which is determined by the extent of cellular damage, site of lesion, degree of disruption of connective tissue sheaths that surround the nerve, associated injuries, age, and general health of the patient. ${ }^{38}$

After peripheral nerve injury, a complicated sequence of events commences to begin the reparative process, but this process is unique because it does not involve mitosis and cellular proliferation. ${ }^{18}$ Although some of the peripheral nerve injuries recover spontaneously, most of them require surgical intervention. Despite over 150 years of experience in modern surgical management of the peripheral nerves, even meticulous surgical repair cannot guarantee full functional recovery, since the surgeon has no control over the "biological battlefield" occurring inside damaged nerves. ${ }^{78}$

\section{History}

The first report of acute nerve injury can be traced to 3,500 years ago. Jacob experienced a sciatic nerve injury with a traumatic hip dislocation during his battle with the angel in the well-known biblical story (Genesis 32:25-33). ${ }^{24}$ Hemophilus differentiated peripheral nerves from tendons in $300 \mathrm{BC}$. He traced nerves to the spinal cord to demonstrate the continuity of the nervous system. ${ }^{87}$ The first reference to nerve repair was by Rhazes in AD 900, but peripheral nerve regeneration after nerve repair was demonstrated by Cruikshank in 1795. Nelaton described the secondary nerve repair in 1864, and primary epineural nerve suture concept was introduced by Hueter ${ }^{25}$ in 1871. Mikulicz described the sutures that reduced tension on the nerve suture 


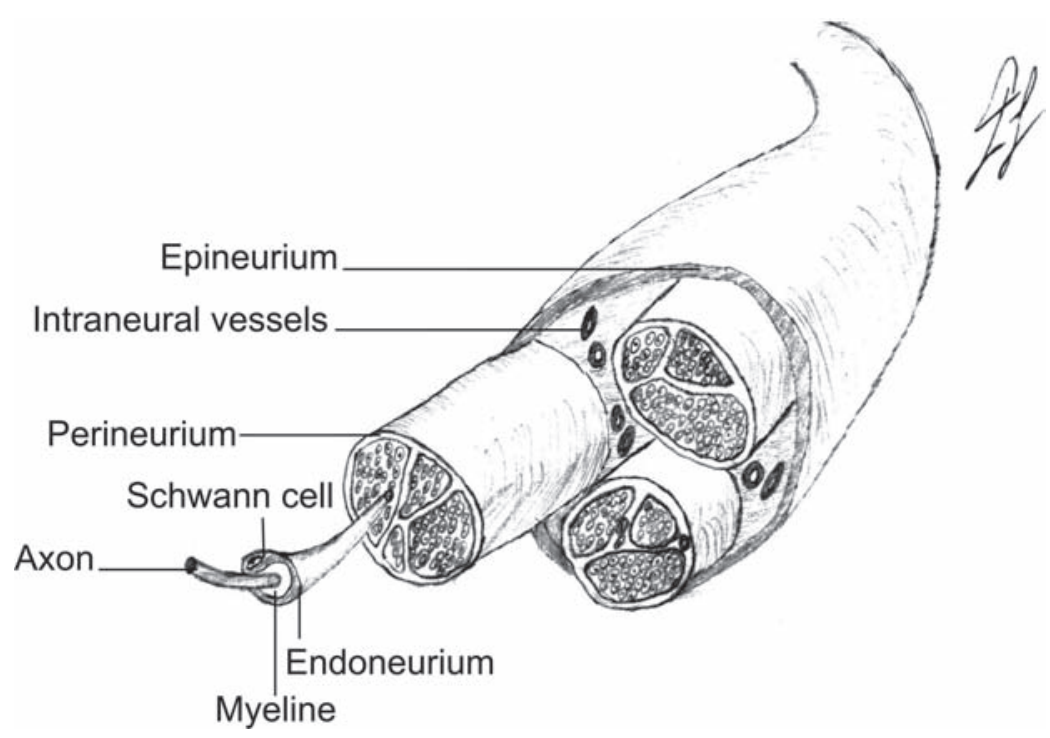

Figure 37.1. A myelinated peripheral nerve branch with associated structures, including epineurium, perineurium, endoneurium, intraneural vessels, Schwann cell, axon, and myelin.

in 1882, and Loebke described bone shortening to decrease the tension on the suture line in 1884 . Albert described grafting nerve gaps in 1876 . Cajal pioneered the concept of axonal regeneration from neurons and their guidance by chemotropic substances. Plenty of experience in evaluation and treatment of traumatic nerve injuries was gained in wartimes. During World War I, nerve injuries were repaired under tension and risked disruption after repair because of extensive soft tissue injuries and significant infections. After World War II, in 1945 Sir Sunderland demonstrated the detailed internal anatomy of the major peripheral nerves and developed microsurgical techniques to improve nerve repair outcomes. ${ }^{87}$

\section{Peripheral Nerve Anatomy}

All members of the mammalian system have the same peripheral nervous system anatomy. In the peripheral nervous system, nerve fibers are ensheathed by Schwann cells, either individually in case of myelinated fibers or in groups in the case of unmyelinated fibers. They form the sheath covering the axons in myelinated peripheral nerves, and they form basal membrane in unmyelinated nerves. The basal lamina layer envelops Schwann cells and supports axonal regeneration. Myelinated and unmyelinated nerve fibers are embedded within a connective tissue compartment called endoneurium. Endoneurium is the layer that covers and nourishes the axons. The endoneurium is encircled by a compact layer called the perineurium, which is a key component in nerve strength. The perineurium partitions nerve fibers into fascicles. These nerve fascicles are embedded within a connective tissue compartment called the internal epineurium. Epineurium is the connective tissue layer of the peripheral nerve, which both encircles and runs between fascicles. Its main function is to nourish and protect the fascicles. The outer layers of the epineurium are condensed to form a sheathlike structure that forms the external epineurium..$^{58}$ The perineurium and the nonfenestrated endothelium in the endoneural vessels form the blood nerve barrier, which blocks the infiltration of cells into the endoneural environment of the peripheral nerve (Figure. 37.1).

\section{Nerve Injury Classification}

Nerve injuries were classified by Seddon ${ }^{80}$ in 1947 , and Sunderland ${ }^{87}$ further refined this classification in 1951.

Seddon classified nerve injuries into three major groups: neuropraxia, axonotemesis, and neurotemesis. Neuropraxia is characterized by a localized conduction deficiency and local myelin damage, usually secondary to compression. 
PERIPHERAL NERVE INJURIES

Axon continuity is preserved and the nerve does not undergo distal degeneration. Axonotemesis is defined as loss of continuity of axons, with preservation of the connective tissue elements of the nerve. Wallerian degeneration is seen distal to the trauma zone. Neurotemesis is the most severe injury, equivalent to physiologic disruption of the entire nerve; it may or may not include actual nerve transactions. ${ }^{80}$

The Sunderland classification is based on the widely variable prognoses of axonotemetic injuries. Axonotemesis grade is divided into three types in this classification depending on the fascicular structure coverage. Neuropraxia is equivalent to Sunderland type 1 injury. In Sunderland type 2 injury, the endoneurium and the epineurium are still intact. Complete functional recovery can be expected, because the regenerating axons from the proximal segment are directed along their original course. The time for recovery is directly related to the level of injury because of the need for axon regeneration distally to the end organ. In a Sunderland type 3 injury, the endoneurium is disrupted, but the perineurium and endoneurium are intact. Endoneurium fibrosis, which hinders axonal regeneration, occurs because of this disruption, and recovery is incomplete unless the intrafascicular fibrosis is excised. If there is severe retrograde injury to cell bodies, which either destroys neurons or slows their recovery with longer delays, end organ changes may develop and the recovery will be incomplete. In a Sunderland type 4 injury, there is full-thickness fibrosis formation, and only the epithelium is intact. Retrograde neuronal damage is intensified. This type of injury requires excision of the damaged segment and surgical repair or reconstruction of the nerve. Sunderland type 5 injury is equivalent to Neurotemesis, and it is characterized by complete nerve disruption. Recovery is impossible without surgical intervention. ${ }^{87}$ In 1988, Mackinnon and Dellon presented a "type 6" injury that represented a complex peripheral nerve injury. This grade involved combinations of Sunderland's grades of injuries. ${ }^{57}$

\section{Nerve Degeneration}

Waller described the degenerative changes developing in the distal nerve after nerve transaction in 1850, which was later called "Wallerian degeneration." Just after nerve injury, myelin starts to break down. Axonal and myelin debris are removed by the phagocytic action of macrophages and
Schwann cells, a process that can take from 1 week to several months. Schwann cells become active within $24 \mathrm{~h}$ after injury, exhibiting nuclear and cytoplasmic enlargement as well as an increased mitotic rate. Schwann cells appear to ingest axonal and myelin debris, and then pass this on to macrophages. Same changes also occur in the proximal end of the injury for a varying distance, depending on the severity of the injury. Endoneural sheath of the nerve fibers form the tubes called "Bands of Bungner," which are organized by the proliferating Schwann cells, and they are the potential tubes into which the nerve sprouts will grow. ${ }^{57}$

\section{Nerve Regeneration}

Within the first $24 \mathrm{~h}$ following nerve injury, while Wallerian degeneration continues distally, axons from the proximal segment start to sprout at the same time. Multiple axons are produced from each axon. These axons are unmyelinated at the beginning even when the axon from which they have originated is myelinated. As the regenerating units mature, they become myelinated fibers, and functional recovery can be seen. If these regenerating fibers cannot reach appropriate distal routes and are lost in the extraperineural environment, then a neuroma will form, which represents a potential loss of functional recovery and may be a source of neurogenic pain. There is a growth cone that consists of filopodia rich in actin in the distal part of regenerating axons. The tips of the filopodia will explore the distal environment, and if they are in contact with the basal lamina of the Schwann cell, they draw the entire growth cone distally. The axonal sprout regenerating rate toward the distal segment ranges between 1 and $4 \mathrm{~mm} /$ day. $^{57,58}$

\section{Nerve Repair}

Peripheral nerves that are interrupted by trauma or surgical resection of a mass require reapproximation of their ends. Nerve repairs may be primary or secondary depending on the time of repair after injury.

Primary repair is a direct reconnection of the nerve after disruption of its continuity. Historically it was thought that the best approach is to wait 3 weeks before repair to allow for completion of the Wallerian degeneration process, but Mackinnon et al. have shown that immediate repair is associated with better results. ${ }^{58}$ 
Prerequisites for early repair are a clean wound, good vascular supply, no crush component to the injury, and adequate soft tissue coverage.

Secondary repairs are delayed repairs that may contain different strategies when the prerequisites of primary repair cannot be met. However, within 3 weeks after injury, a nerve may lose as much as $8 \%$ of its length. ${ }^{94}$

An end-to-end repair is preferred if the gap is small, and the two ends can be approximated with minimal tension. Best results occur when the nerves are either purely sensory or purely motor and when the intraneural connective tissue component is small, which can vary from $22 \%$ to $80 \% \cdot{ }^{93,94}$ End-to-end nerve repair techniques are "Epineural repair," "Group-fascicular repair," and "Fascicular repair." Sharp lacerations without loss of nerve substance or partial lacerations with proper alignment are good examples of injuries that benefit from epineural repair. In a crushing or delayed repair requiring trimming of nerve ends, group-fascicular repair improves fascicular alignment without an excessive number of sutures. Excessive sutures add to scar tissue production. Fascicular repair is not practiced widely, because it requires numerous sutures, and it is technically difficult. ${ }^{94}$ Proponents argue that group-fascicular repair is better, because axonal alignment is more accurate with this technique. However, others have shown that there is no functional difference in outcome between epineural and group-fascicular repair. Furthermore, group-fascicular repair has the potential disadvantage of increased scarring and damage to the blood supply as a result of the additional dissection. Lundborg et al. ${ }^{55}$ showed that although this technique ensures correct regeneration of regenerating axons, there is little evidence that it is superior to the less exact but simpler epineural repair.

"Epineural sleeve neurorrhaphy" is another nerve coaptation technique introduced by Siemionow et al. ${ }^{82}$ It is a modification of the "epineural cuff" technique described by Snyder et $\mathrm{al}^{83}$ before. In epineural sleeve technique, the free edge of the epineurium at the distal stump is rolled back and a 2-mm nerve segment of the distal nerve stump is resected. The epineural sleeve created is then pulled over the proximal nerve end to cover the coaptation site and is anchored to the epineurium $2 \mathrm{~mm}$ proximal to the coaptation site with two sutures placed $180^{\circ}$ apart. In this study, it was proven that epineural sleeve neurorrhaphy technique revealed faster functional recovery when compared with conventional end-to-end nerve coaptation. This finding was attributed to the fact that in this technique no tension or compression was created at the repair site. Instead, the tension was applied to the epineural sleeve, which is proximal to the coaptation site. In addition, the epineural sleeve provides a biologic chamber at the coaptation site, where axoplasmic fluid is collected, leaving a perfect milieu for regeneration of the nerve. Finally, perfect fascicular matching without bulging was possible using this technique, because the nerve's own epineurium guided the alignment of regenerating fascicles. Faster functional recovery has been shown in the experimental model with this technique, but it has to be verified clinically. ${ }^{89}$

Although the classic technique of neurorrhaphy is devoid of tension, Hentz et al. ${ }^{40}$ studied a primate model and showed that direct nerve repair under modest tension actually does better than a tension-free nerve graft over the same regenerating distance.

\section{Neuroma in Continuity}

A neuroma in continuity may arise like a bulbous swelling as a sequel to peripheral nerve injury. This lesion may be composed of some functional and nonfunctional fascicular components, which have to be determined by a careful preoperative assessment. Effective treatment of a painful neuroma remains as a challenging problem, because it is possible that the surgeon may sacrifice the functional fascicles while trying to repair the nonfunctional fascicles of the nerve. ${ }^{63}$

A sharp pain associated with a scar and functional loss in the distribution of the involved nerve is typical for neuroma in continuity. The character of pain and its psychological implications are important in the selection of patients for surgery.

In the surgical treatment of the neuroma in continuity, fascicles may be separated by microneurolysis and regenerating axons are directed appropriately to distal ones when the nerve stumps and surgical bed are suitable for this. The functional fascicles can be identified proximal and distal to the injury site via electrodiagnostic testing. These fascicles are preserved, and potentially damaging dissection within the neuroma incontinuity should be avoided. ${ }^{60}$ 

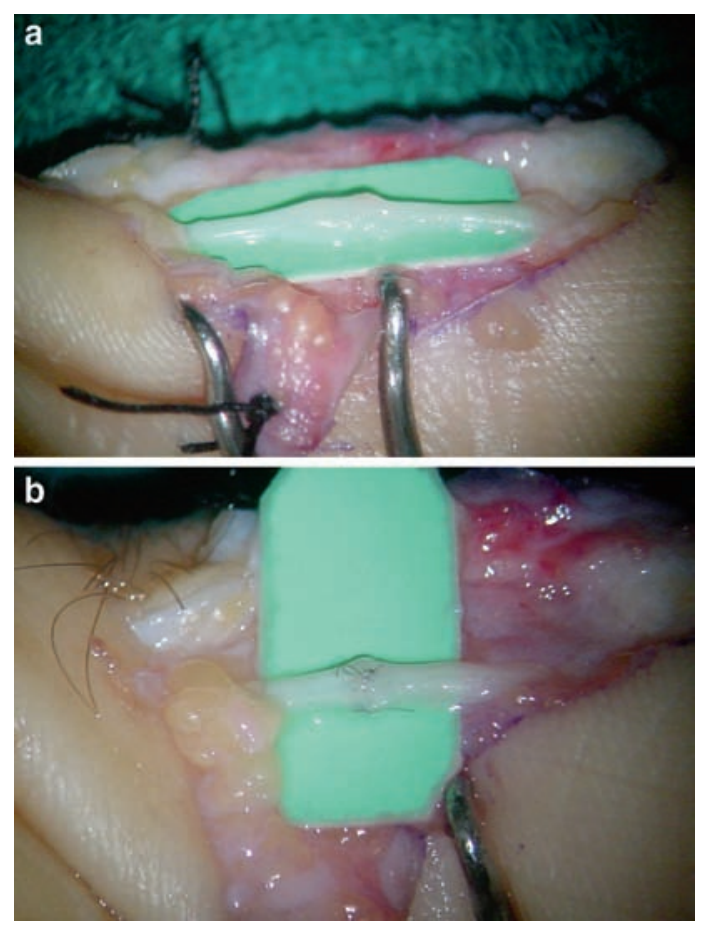

Figure 37.2. (a) A neuroma in the continuity of the digital nerve. (b) Epineural end-to-end repair of the digital nerve after excision of the neuroma.

When there is insufficient length for tensionfree end-to-end repair, a nerve graft can be used. The second alternative for painful neuroma treatment is resection of neuroma and transposition of the proximal stump into muscle (or bone, e.g., in digits) for noncritical or function distal nerves, in cases of previous treatment failure, or if the wound bed is not suitable for neural repair $^{72,74,97}$ (Figures 37.2 and 37.3).

\section{Nerve Sheath Tumors}

Neurofibroma (from Schwann cells and fibroblasts), neurilemmoma (from Schwann cells), and neurofibrosarcoma (from Schwann cells and fibroblasts) are the three types of tumors originating from intrinsic cells of the nerve.

\section{Neurofibroma}

Neurofibromas are usually seen with neurofibromatosis. They rarely cause some symptoms like pain or paresthesia, and their usual location is
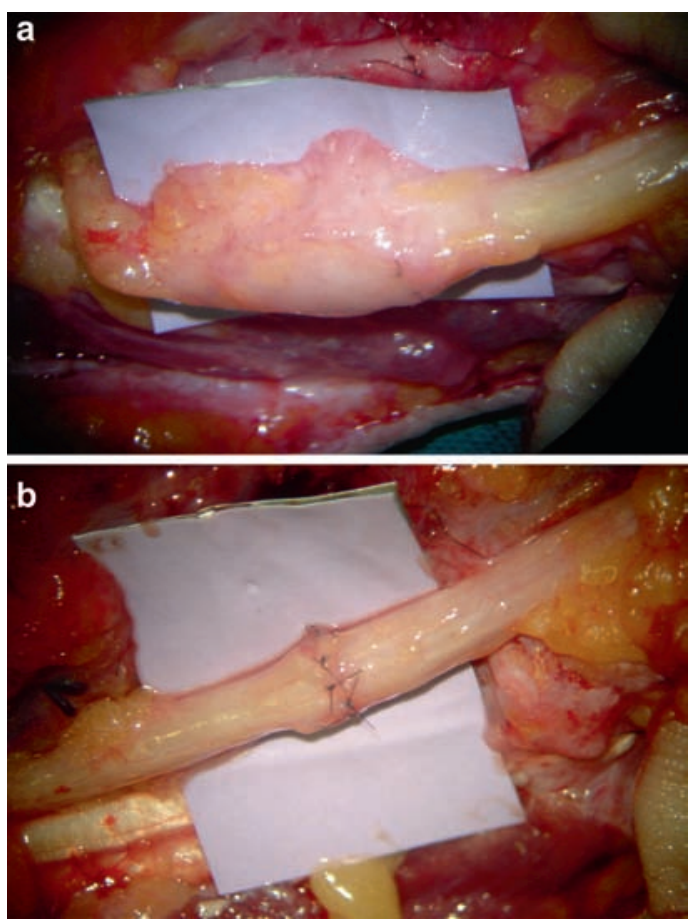

Figure 37.3. (a) A neuroma in the continuity of the ulnar nerve. (b) Epineural end-to-end repair of the ulnar nerve after excision of the neuroma

along peripheral nerves. They are nonencapsulated fusiform tumors, composed of excess of cells within nerve fascicles. ${ }^{65,92}$

If the tumor size is small without causing major neurological deficit, simple enucleation is recommended. If the tumor size is large, with major neurological symptoms, en bloc resection of the tumor with the peripheral nerve is the treatment of choice. ${ }^{43,92}$ (Figure. 37.4).

\section{Neurilemmoma}

Neurilemmomas (also called "schwannoma" and "neurinoma") mostly arise from major mixed (motor and sensory) nerves and are solitary unless the patient has neurofibromatosis (von Recklinghausen's disease). They are well-encapsulated tumors, composed of differentiated Schwann cells. Large neurilemmomas may cause some neurological symptoms such as paresthesia and pain, but the small ones are usually asymptomatic. Surgical dissection of the tumor from the nerve is the treatment of choice, and recurrence is rare after excision of neurilemmomas ${ }^{65,92}$ (Figure. 37.5). 

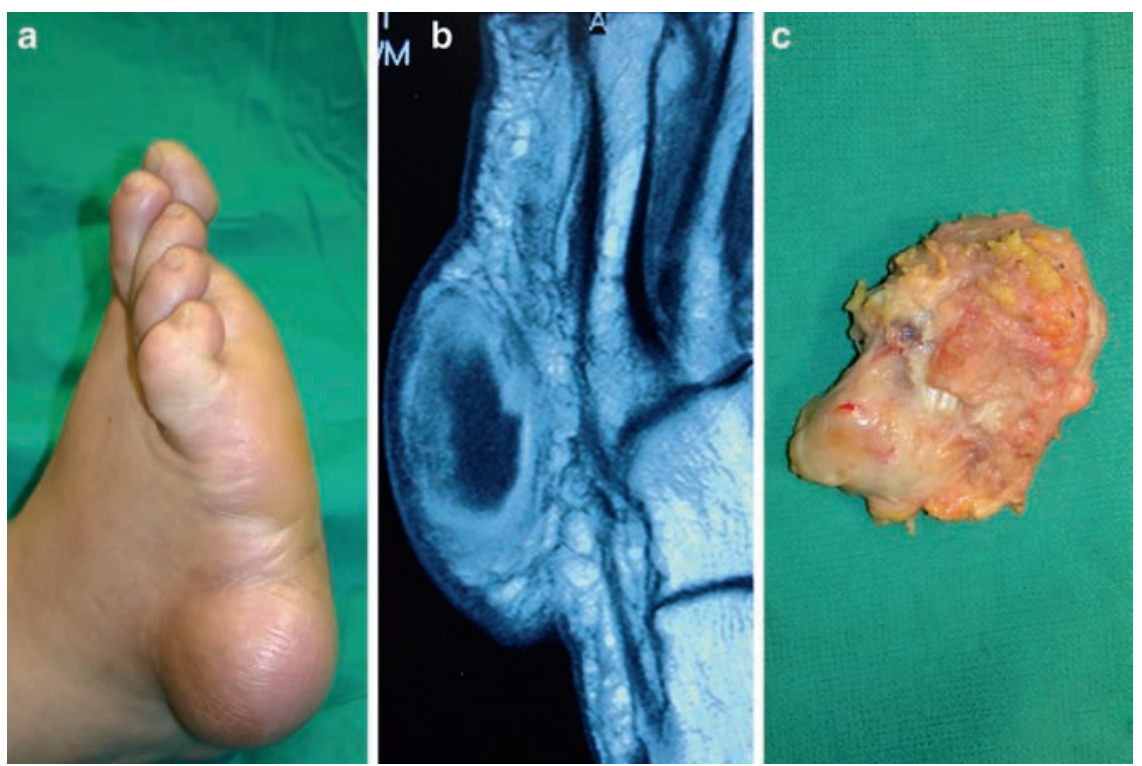

Figure 37.4. (a) A case of neurofibroma of the lateral aspect of the foot. (b) Magnetic resonance imaging confirming neurofibroma lesion. (c) Neurofibroma measuring $5 \mathrm{~cm} \times 2 \mathrm{~cm}$ after excision.
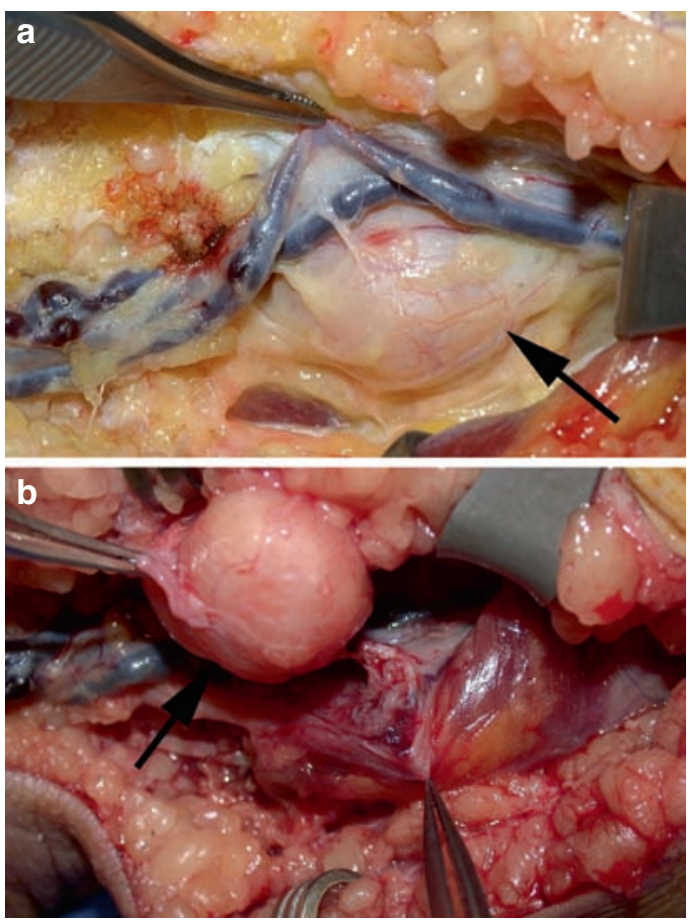

Figure 37.5. (a) Neurilemmoma (arrow) of the posterior tibial nerve above the medial malleolus of the foot. (b) Posterior tibial nerve after resection of the tumor (arrow).

\section{Neurofibrosarcoma}

This is a highly malignant tumor, which is found either in a patient with neurofibromatosis or in patients who have undergone radiotherapy. Neurofibrosarcoma may be termed a malignant schwannoma, since the tumors arise from the sheath of Schwann cells covering neural tissues. Radical excision followed by chemotherapy and radiotherapy is the treatment of choice in this aggressive tumor, and patients with neurofibrosarcomas have recurrence rates of more than $10 \% .{ }^{21,31,33,50,62}$

\section{Compressive Neuropathies}

Although any nerve in the body can be compressed, certain nerves are more vulnerable because of their anatomic locations. The common symptoms include pain, sensorial deficit, and motor loss. Diagnosis is based on physical examination, whereas electrodiagnostic and imaging studies help to confirm the diagnosis and provide information regarding the recovery potential. ${ }^{85}$ 


\section{Upper-Extremity Compressive Neuropathies}

\section{Carpal Tunnel Syndrome}

Carpal tunnel syndrome (CTS) is the most frequent nerve compression syndrome. The median nerve is compressed inside the carpal canal by the transverse carpal ligament at the wrist. This compression may be caused by intrinsic (inside the carpal canal) or extrinsic factors (outside the carpal canal). CTS may be related to congenital, traumatic, metabolic/endocrine, inflammatory, infectious, or idiopathic causes. In addition, repetitive use is thought to increase the incidence of CTS. ${ }^{35}$

Physical examination may reveal percussion tenderness of the median nerve at wrist region (Tinnel's sign). Sensory deficits such as decreased sensation to light touch or pain may be present in the radial three digits. ${ }^{12}$ Weakness of the abductor pollicis brevis and atrophy of the thenar muscles are common in the late phases of the disease. Many tests have been described for CTS such as Phalen's test, reverse Phalen's test, compression test, tourniquet test, closed fist test, "flick sign," and hand elevation test. Electrodiagnostic tests are helpful in the conformation of the diagnosis and to show the severity of the condition and also in differential diagnosis.

Treatment options for CTS can be categorized as operative and nonoperative. Nonoperative options include activity modifications to avoid exacerbating positions, nonsteroidal antiinflammatory drugs (NSAIDs), splinting the wrist at neutral position, steroid injections to carpal tunnel, pyridoxine, and diuretics. In cases of nonoperative treatment failure or in advanced cases, operative treatment is indicated. ${ }^{36}$ Surgical treatment may be classified as open and closed techniques. In the classic open technique, transverse carpal ligament is released under direct visualization via a mid-palmar incision. ${ }^{2}$ In the closed technique (endoscopic), mid-palmar incision is avoided. Earlier recovery and return to work than the open release has been shown in some studies. Neurovascular complication incidence is not increased in the closed technique. ${ }^{8,95}$ Incomplete release and longer operation time are among the disadvantages of closed technique, particularly at the beginning of the learning curve $^{1,16}$ (Figure. 37.6).

\section{Anterior Interosseous Nerve Syndrome (Kiloh-Nevin Syndrome)}

Anterior interosseous nerve is compressed in the forearm region by various anatomic structures. It may be compressed by the deep head of pronator teres and other fibrous bands or vessels in the forearm region.

Patients present with weakness of flexor pollicis longus, flexor digitorum profundi (of second and sometimes third digit), and pronator quadratus muscles of the affected hand. These patients are unable to make the shape of letter "O" between first and second digits. Electrodiagnostic tests are particularly helpful for its differentiation from the "pronator syndrome."

Its treatment is usually surgical release of the structures compressing the median nerve in the forearm region such as lacertus fibrosus, deep head of pronator teres, and other structures such as muscles or vessels overlying the interosseous branch of the median nerve, via an S-shaped incision extending from distal arm to proximal forearm. ${ }^{29,85}$

\section{Pronator Syndrome}

The pronator syndrome is described as compression of the sensory branch of the median nerve in the elbow region by the anatomic structures such as pronator teres, the superficial arch of flexor digitorum superficialis, and the bicipital aponeurosis. ${ }^{6}$ Patients suffer from pain in the volar proximal portion of the forearm, which may also extend to the distal arm. Electrodiagnostic motor tests are typically normal. Increased pain with resisted pronation of the forearm and elbow extension (compression of pronator teres), pain with resistance to flexion of the middle finger proximal interphalangeal joint (compression of flexor digitorum superficialis arch), and pain with resisted elbow flexion and forearm supination (compression of bicipital aponeurosis) are the provocative maneuvers in this syndrome. ${ }^{85}$

Conservative treatment is the first choice in these patients. Physical therapy, NSAIDs, and local steroid injections are usually effective in most of the patients. In the resistant cases, the median nerve may be decompressed in the forearm region..$^{69,85}$ 

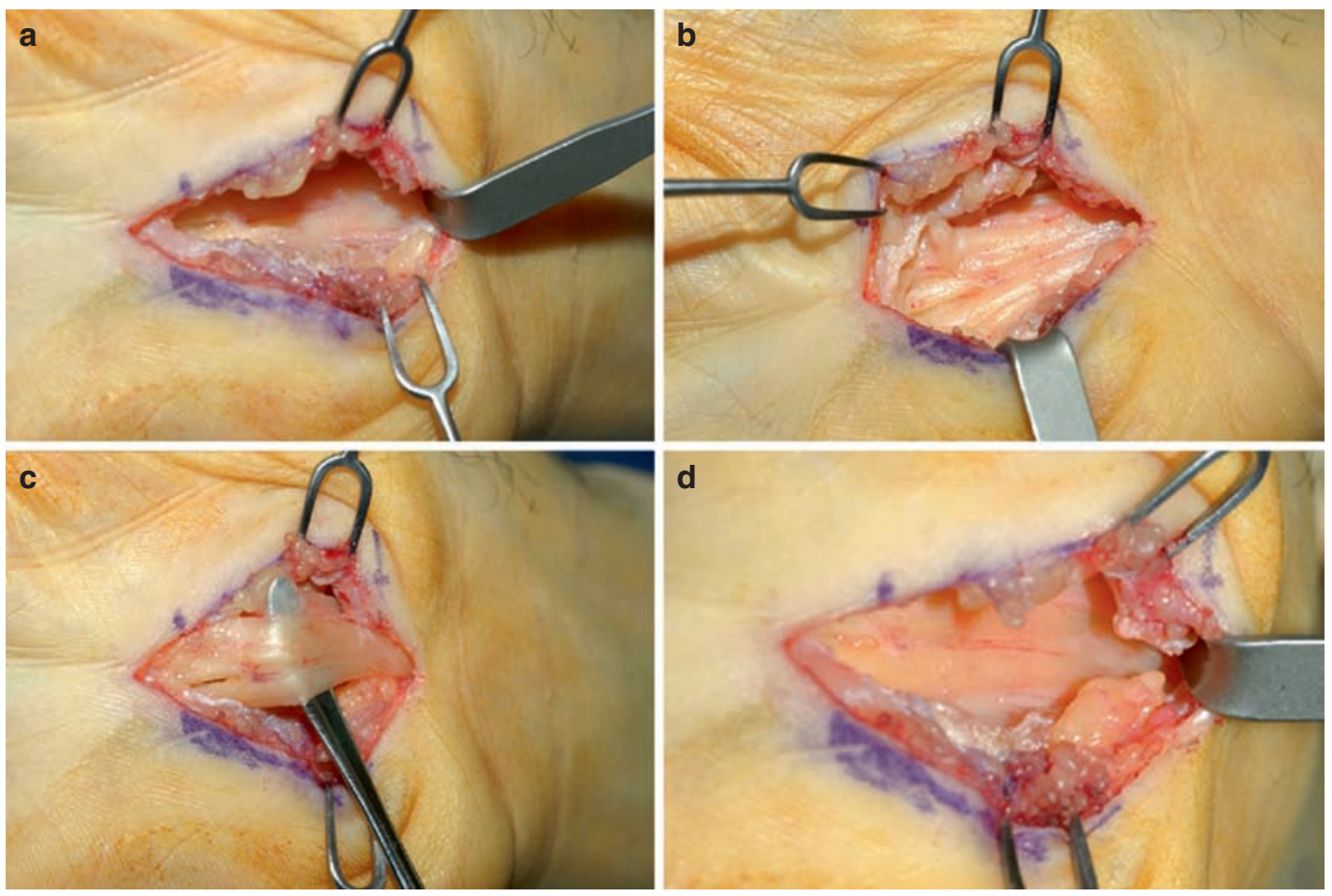

Figure 37.6. Classic open technique of transverse carpal ligament release. (a) Mid-palmar incision. (b) Exposure of the median nerve after transverse carpal ligament release. (c) Presence of engorged vasonervorum after median nerve decompression. (d) Median nerve within carpal tunnel following release.

\section{Ulnar Tunnel Syndrome}

In this syndrome, ulnar nerve is compressed within Guyon's canal. Trauma, soft tissue masses, and variant muscular and vascular anomalies may cause this compression. ${ }^{37}$

Patients may present with intrinsic muscle weakness of the affected hand, wrist pain, and diminished sensation in the cutaneous dermatome of the ulnar nerve of the affected hand. Motor weakness of the adductor pollicis, hypothenar, and interosseous muscles with positive Wartenberg's sign may be seen. Diminished sensation on the ulnar site of the palm, with normal sensation on the dorsum of the hand, differentiates the distal ulnar nerve compression from a more proximal site than the wrist region. Froment's sign and Phalen test may be positive in this syndrome. ${ }^{85,98}$

Surgical decompression is required in most of the patients, while conservative treatment can be tried in patients with mild symptoms. Ulnar nerve can be decompressed via a curvilinear incision that is centered on the hook of hamate in this region. It is important to decompress both superficial and deep branches of the ulnar nerve..$^{30}$

\section{Cubital Tunnel Syndrome}

It is the second most common entrapment syndrome after CTS. In this syndrome, the ulnar nerve is typically compressed beneath the cubital tunnel retinaculum at the elbow. This compression may be spontaneous due to repetitive and sustained elbow flexion, presence of mass, arthritic spur, synovitis, and anatomic variations (e.g., anconeus epitrochlearis).$^{85}$

Medial elbow pain with dorsoulnar-sided palm and digit paresthesias or dysesthesias may be the symptoms of these patients. Intrinsic muscle weakness and hand clumsiness are late symptoms. ${ }^{19}$ Tenderness over the elbow at the level of the medial epicondyle may be revealed by examination of the patient. Electrodiagnostic testing reveals motor weakness of the flexor digitorum profundus, flexor carpi ulnaris, and interosseous muscles and slowing at the elbow level. ${ }^{14}$ 

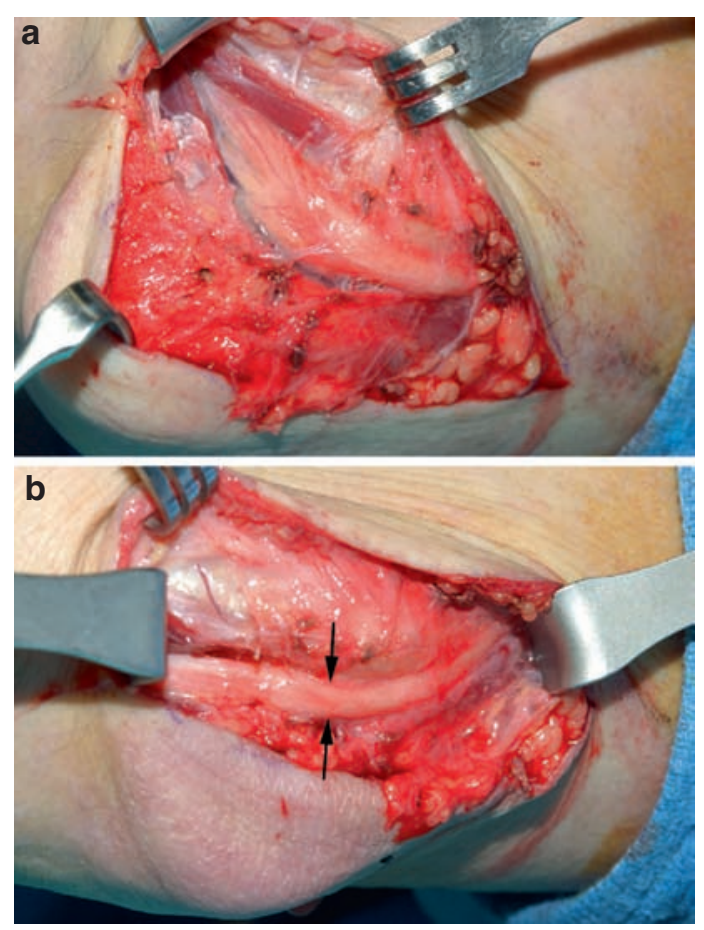

Figure 37.7. Cubital tunnel release. (a) Exposure of the ulnar nerve within the ulnar nerve groove. (b) Ulnar nerve after decompression showing narrowing at the compression site (arrows).

Conservative treatments such as an activity modification, NSAIDs, and nighttime elbow splint are beneficial in some patients. ${ }^{28}$ Operative treatment is indicated if the nonoperative treatment fails. Decompression of the ulnar nerve with or without medial epicondylectomy and ulnar nerve transposition are performed as a surgical treatment ${ }^{75}$ (Figure. 37.7).

\section{Posterior Interosseous Nerve Compression}

Posterior interosseous branch of the radial nerve is compressed in the proximal forearm region in this disease. The most common site of compression is the Arcade of Frosche (proximal edge of supinator muscle), followed by fibrous bands in the vicinity of the radiohumeral joint, vascular malformations (leash of Henry), tendinous edge of the extensor carpi radialis brevis, and substance or distal edge of the supinator muscle. ${ }^{4}$

Forearm pain with extensor weakness is the typical symptom of these patients. Physical examination reveals varying degrees of finger or thumb drop without sensory deficit. Surgery is the treatment of choice via anterior (Henry) or posterior (Thompson) approach. ${ }^{53}$

\section{Radial Tunnel Syndrome}

Radial tunnel syndrome is attributed to the cases of proximal forearm pain caused by compression of the posterior interosseous nerve without motor paralysis. Electrodiagnostic studies are usually normal. Local nerve blockade may be useful in differential diagnosis of this syndrome. ${ }^{32}$ Long-term conservative treatment with physical therapy is recommended. Surgery is indicated in resistant cases via the Thompson approach. ${ }^{85}$

\section{Posterior Interosseous Nerve Syndrome}

"Arcade of Frohse" (proximal edge of the supinator muscle) is the most common site where the posterior interosseous nerve is compressed in this syndrome. These patients present with weakness or paralysis of the extensors of the wrist and digits. Vague forearm pain may accompany the symptoms, without any sensory deficit. Conservative treatment with physical therapy is recommended for 6-12 weeks, and surgery is indicated if no improvement occurs. ${ }^{53}$

\section{Wartenberg Syndrome}

Patients with Wartenberg syndrome present with pain over the distal radial forearm along with paresthesia on the dorsal radial hand, which is associated with the compression of the superficial radial nerve at the wrist near the radial styloid. This nerve is susceptible to compression in this region due to extrinsic compression, trauma, surgery, or repetitive movement. Most of the patients are treated nonoperatively, including rest, splinting, and removal of the compression sources. Surgery is indicated in resistant cases ${ }^{53,84}$ (Figure. 37.8).

\section{Lower-Extremity Compressive Neuropathies}

\section{Lateral Femoral Cutaneous Nerve Compression (Meralgia Paresthetica)}

The lateral femoral cutaneous nerve (LFCN) may be compressed by the inguinal ligament. Dysesthesia and hypesthesia of the lateral thigh region are common in these patients. Tinnel's sign may be present on the tract of LFCN under the inguinal ligament. ${ }^{61,91}$ 

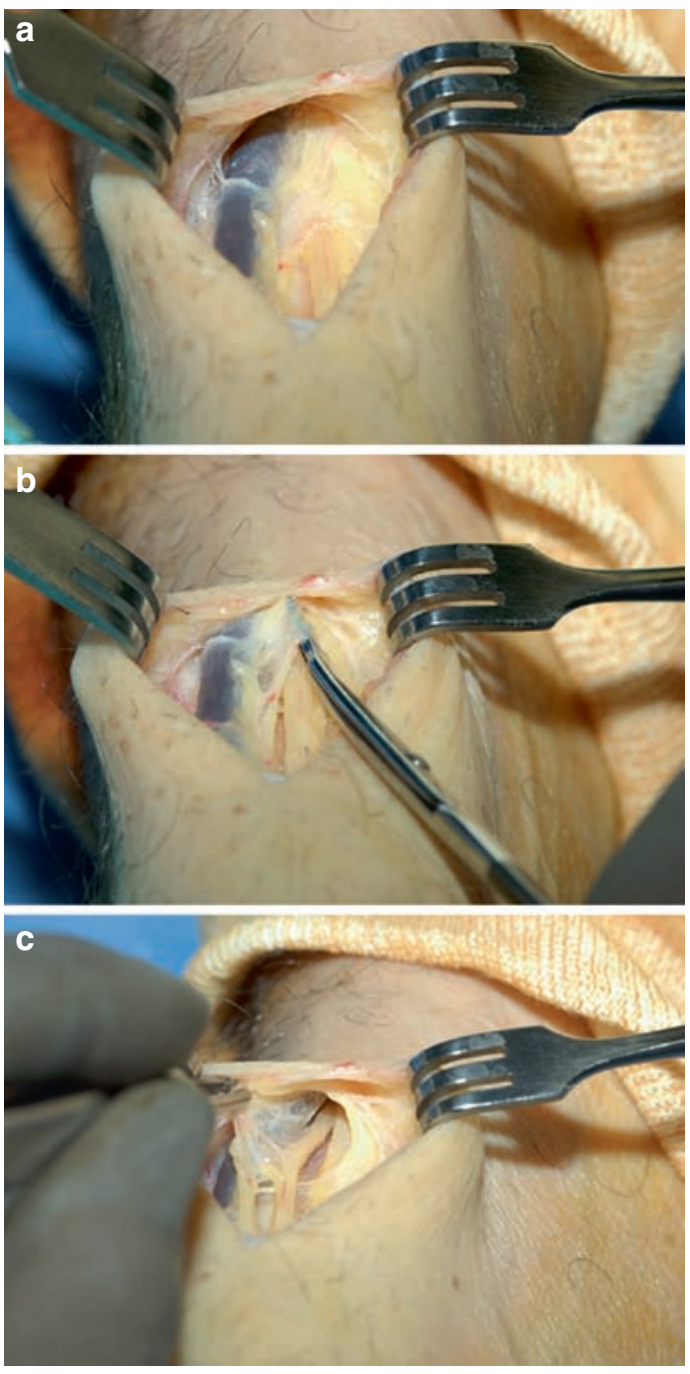

Figure 37.8. Surgical decompression of the superficial radial nerve at the wrist region. (a) Exposure of the superficial radial nerve. (b) Decompression of the superficial radial nerve. (c) Superficial radial nerve after decompression.

Electrodiagnostic tests are not used in this nerve entrapment. Adjustment in the posture may be the first treatment of choice, but if this fails, surgical decompression with transaction of the inguinal ligament is indicated. ${ }^{46,61}$

\section{Common Peroneal Nerve Compression}

It is the most common nerve entrapment of the lower extremity. The common peroneal nerve is compressed at the region of the neck of fibula. Patients present with sensorial deficit in the anterolateral aspect of the leg and dorsum of the foot. Foot drop is accompanied in more advanced cases. ${ }^{42,91}$

Although most of the cases were caused by traumas, bony tumors, and ganglia, it has also been reported in athletes due to repetitive trauma or nerve traction injury. ${ }^{68}$ Surgical decompression is the treatment of choice in most of the cases via curvilinear incision over the neck of fibula ${ }^{90}$ (Figure. 37.9).

\section{Tarsal Tunnel Syndrome}

Tarsal tunnel syndrome is the compression of the tibial nerve in the tarsal tunnel in the ankle region. Systemic illnesses such as diabetes mellitus, alcoholism, and hypothyroidism were reported to accompany this syndrome. ${ }^{10,34}$

Sensorial deficit and pain in the plantar region are the symptoms associated with this syndrome. Intrinsic muscle atrophy with clawing of the toes is seen in advanced cases. Electrodiagnostic tests are usually diagnostic. Operative treatment is the treatment of choice via longitudinal incision between the medial malleolus and calcaneus ${ }^{91}$ (Figure. 37.10).

\section{Nerve Repair Using Autograft}

Although direct nerve repairs demonstrated better results than nerve grafts, nerve grafts revealed superior results when compared with direct repairs performed under undue tension, which produced nerve ischemia. ${ }^{7,49,56,67}$ In a study that evaluated nerve tension as a determinant of nerve ischemia in a rat sciatic nerve model, blood flow was inversely proportional to nerve tension. Chronic nerve injuries required nearly three times more of the baseline blood flow when compared with acute nerve injuries. Although an $8 \%$ elongation was tolerated for both acute and chronic nerve injuries, a $15 \%$ elongation produced a profound decrease in blood flow, which never recovered. When primary repair cannot be performed without undue tension, nerve grafting is required. Acute injuries retract only $4 \%$, making primary end-to-end repairs possible, whereas the $28 \%$ retraction in delayed repairs cannot be overcome by nerve elongation, and nerve grafts are usually necessary. ${ }^{96}$

Nerve autografts remain the gold standard for nerve grafting. Three major types are cable, trunk, and vascularized nerve grafts. Cable grafts 

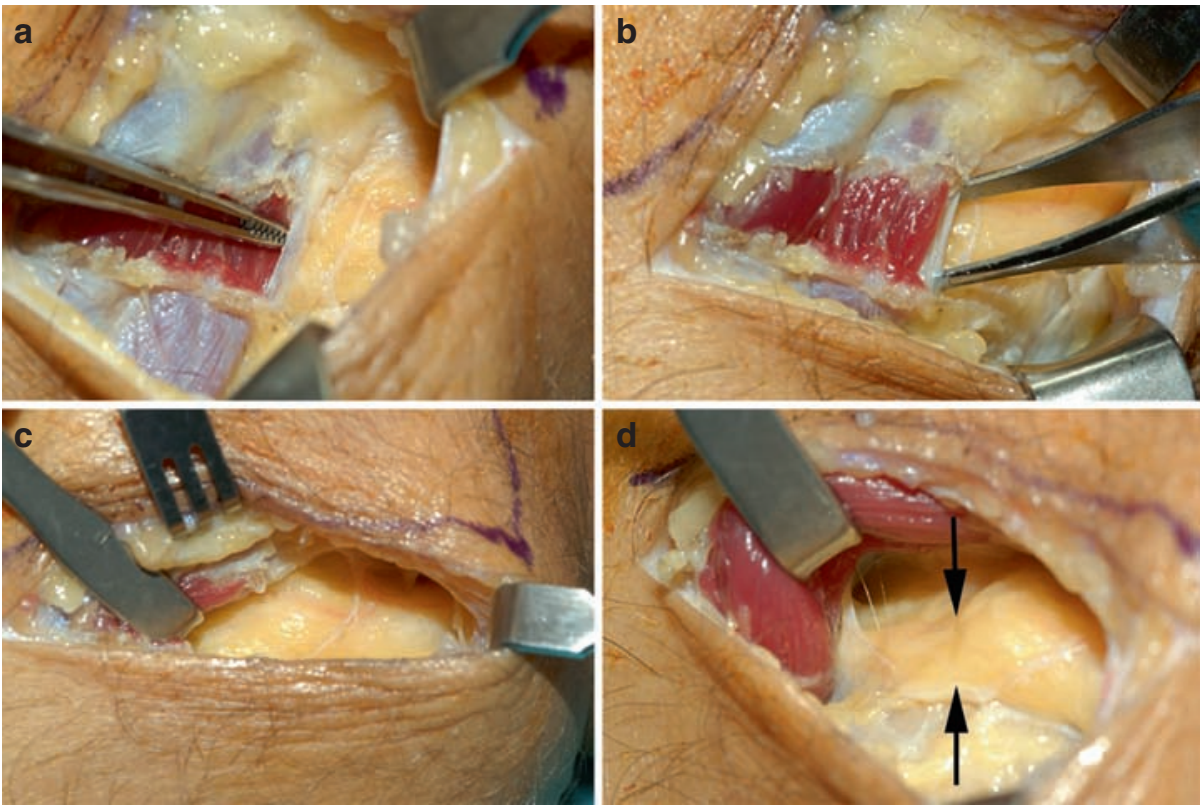

Figure 37.9. Surgical decompression of the common peroneal nerve. (a) Forceps are pointing toward the fascia of the peroneus longus muscle $3 \mathrm{~cm}$ below the fibular neck. (b) Entrance of the common peroneal nerve into peroneus longus muscle after release of the peroneus longus fascia. (c) Common peroneal nerve after decompression and resection of the peroneus longus fascia. (d) The site of common peroneal nerve compression (arrows) on the entrance to the anterior compartment underneath the peroneus longus muscle, which is elevated by the retractor.
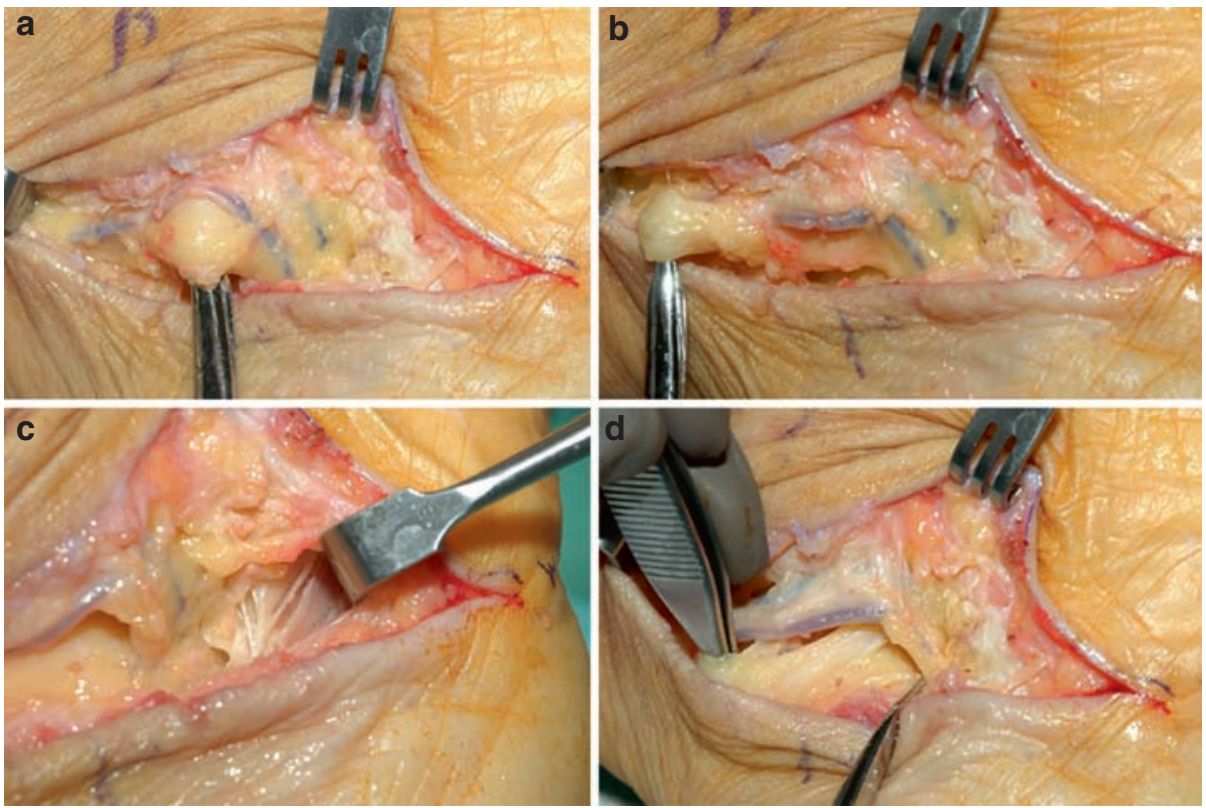

Figure 37.10. Surgical decompression of the posterior tibial nerve in the tarsal tunnel. (a) Decompression of the posterior tibial nerve after release of flexor retinaculum. (b) Decompressed posterior tibial nerve. (c) Decompression of the medial plantar nerve; retractor is holding abductor hallucis muscle. (d) Medial plantar nerve entering medial plantar tunnel after decompression. 
may be single or multiple small-caliber nerve grafts aligned parallel to span a gap between fascicular groups. The senior author, Siemionow, evaluated the single-fascicle technique for neural deficit repair and proved that a single-fascicle graft resulted in faster functional recovery and better morphologic outcome compared with conventional nerve repair. ${ }^{89}$

Trunk grafts are mixed motor-sensory whole nerve grafts. They have been associated with poor functional results in large part due to the thickness of the graft and the consequent diminished ability to revascularize after implantation.

Vascularized nerve grafts have been used in the past but with conflicting results. They may be considered if a long graft is needed in a poorly vascularized bed. Because of donor-site morbidity, vascularized grafts have been used mainly in brachial plexus injuries. ${ }^{51}$

The most common source of autografts is the sural nerve, which is easily obtainable and relatively dispensable. Other autograft sources include the anterior branch of the medial antebrachial cutaneous nerve and the superficial radial sensory nerve. ${ }^{87}$ After end-to-end nerve repair using a nerve autograft, Wallerian degeneration will be seen distal to the coaptation site.

\section{Conduits}

Neural conduits are biological (veins) or synthetic structures that guide the regenerating axons to the distal nerve stump. Many researchers have studied different types of conduits that can be used as alternatives to nerve autografts. Both biodegradable and synthetic nonbiodegradable materials, with or without impregnation of growth factors and Schwann cells, have been investigated.

Lotheissen ${ }^{52}$ was the first to use gelatin conduits in 1901. In the 1940s, Weiss and Taylor ${ }^{100}$ and in the 1960s, Braun ${ }^{11}$ and Leeger studied the effects of gelatin on nerve generation. In 1984, Colin and Donoff ${ }^{22}$ reported good results by using collagen conduits, which were comparable to nerve autografts. Navaro et al. ${ }^{73}$ used lamininfilled collagen tubes in 3-5 mm of nerve defects with successful results. Takashi et al ${ }^{88}$ reported successful results using collagen conduits filled with a collagen matrix in nerve defects of $3 \mathrm{~mm}$. Silicone: poly(dimethylsiloxane), ${ }^{54}$ poly(glycolide), ${ }^{99}$ poly(3-hydroxybutyrate), ${ }^{103}$
poly(L-lactide), ${ }^{101}$ Chitosan, ${ }^{45}$ D-glucosamine, ${ }^{102}$ Polyester urethane, ${ }^{9}$ poly 2-hydroxyethylmethacrylateco-methylmethacrylate ${ }^{27}$ are the other materials used as conduits so far.

The materials investigated to date are not without disadvantages, such as the induction of scarring, foreign body reactions, conduit collapse, and invasion by scar tissue. Other drawbacks include the technical difficulty of performing the procedure and often the need for a second procedure to remove nonbiodegradable components. None of the conduits has been proven to be as effective as nerve autografts so far. ${ }^{17,86}$

Synthetic nerve conduits can be used for the reconstruction of small-diameter nerves with a defect of not exceeding $3 \mathrm{~cm}$ or with largediameter nerves with a defect of less than $0.5 \mathrm{~cm}$. The use of vein graft as a conduit is recommended only for nerve gaps less than $3 \mathrm{~cm}$ in noncritical areas. ${ }^{70,104}$

\section{Nerve Repair Using Allograft}

Nerve repair with autograft is inadequate when there is an insufficient amount of autologous nerves available for repair of large defects. This prompted the search for alternative means of reconstruction in extensive nerve injuries. Over the past decades some authors, ${ }^{5,15,41,44,48,79}$ particularly Mackinnon et al., ${ }^{59}$ explored the use of host immunosuppression and cadaveric nerve allografts to restore nerve continuity in clinical cases. The cadaveric nerve allograft provides an unlimited graft source without the morbidities associated with autograft reconstruction. Nerve allografts act as viable conduits. Host motor and sensory axons grow to reach host targets via these conduits. Function is provided by the regenerating autologous nerves, and this regeneration is supported by allogenic cells. In order to ensure Schwann cell viability and minimal fibrosis, allograft must be revascularized in an early post-transplant period. ${ }^{66}$

These grafts are rapidly rejected unless appropriate recipient immunosuppression is achieved. The toxicity associated with immunosuppression required to promote graft acceptance must be compared with the relative benefits of reinnervation before nerve allotransplantation can be safely applied in routine clinical practice. ${ }^{66}$ 


\section{Nerve Graft Alternatives}

Another reinnervation technique of a denervated muscle is the "split nerve transfer method." This technique was first described by Conley and Baker ${ }^{23}$ in 1979. Although they reported that this technique was not clinically very effective, there are reports in favor of this technique in the literature. ${ }^{3,26,76}$

Neurotization is another technique used for reinnervation of a denervated muscle, described by Gersuny in 1906. In this technique, the motor nerve is directly implanted into the muscle. Zhasng et al. ${ }^{105}$ reported the formation of motor end plates by this technique in 1986 .

An alternative technique to nerve autograft is "intact nerve bridge" described by McCallister et al. ${ }^{64}$ in 2001. In that study, the authors observed the histological evidence that the intact nerve functioned as a bridge for regenerating axons, which traveled in the outer epineurium of the tibial nerve before entering the distal end-toside coaptated nerve.

\section{Future Developments}

Stem cell supportive therapy and cellular therapeutics such as chimeric cell transplantations are among the current strategies used for tolerance and chimerism induction. Both types of cells may be systemically administered via intravenous or intraosseus routes or may be locally administered. Injections may be also delivered into the synthetic, autologous, or allogenic conduits. ${ }^{20,39,71}$

The promising results of the stem cell injections in nerve regeneration made us design a study with subepineural injection of the mesenchymal stem cell. The short- and long-term results of this study are currently being reported.

Schwann cell seeding is another method that may be used for creating an adequate environment for nerve regeneration. They help inflammatory cells eliminate debris and upregulate the synthesis of trophic factors such as nerve growth factor (NGF) and laminin. ${ }^{20}$

Acellular nerve allografts that contain natural extracellular matrix components and structure but not native cells are another valuable alternative to nerve autograft. They are currently used to study the roles of extracellular matrix components and cellular components on nerve regeneration concomitantly. ${ }^{13,47,77,81}$ All these new technologies will support future studies on nerve regeneration over long nerve gap defects.

\section{References}

1. Agee JM, McCarroll HR, Tortosa RD, Berry DA, Szabo RM, Peimer CA. Endoscopic release of the carpal tunnel: a randomized prospective multicenter study. J Hand Surg [Am.]. 1992;17(6):987-995.

2. Al-Qattan MM. The anatomical site of constriction of the median nerve in patients with severe idiopathic carpal tunnel syndrome. J Hand Surg [Br.]. 2006;31(6):608-610.

3. Arai H, Sato K, Yanai A. Hemihypoglossal-facial nerve anastomosis in treating unilateral facial palsy after acoustic neurinoma resection. J Neurosurg. 1995;82(1):51-54.

4. Arle JE, Zager EL. Surgical treatment of common entrapment neuropathies in the upper limbs. Muscle Nerve. 2000;23(8):1160-1174.

5. Auba C, Hontanilla B, Arcocha J, Gorría O. Peripheral nerve regeneration through allografts compared with autografts in FK506-treated monkeys. J Neurosurg. 2006; 105(4):602-609.

6. Bilecenoglu B, Uz A, Karalezli N. Possible anatomic structures causing entrapment neuropathies of the median nerve: an anatomic study. Acta Orthop Belg. 2005;71(2):169-176.

7. Birch R, Raji AR. Repair of median and ulnar nerves. Primary suture is best. J Bone Joint Surg Br. 1991;73(1):154-157.

8. Boeckstyns ME, Sorensen AI. Does endoscopic carpal tunnel release have a higher rate of complications than open carpal tunnel release? An analysis of published series. J Hand Surg [Br.]. 1999;24(1):9-15.

9. Borkenhagen M, Stoll RC, Neuenschwander P, Suter UW, Aebischer P. In vivo performance of a new biodegradable polyester urethane system used as a nerve guidance channel. Biomaterials. 1998;19(23):2155-2165.

10. Boyer MI, Hochban T, Bowen V. Tarsal tunnel syndrome: an unusual case resulting from an intraneural degenerative cyst. Can J Surg. 1995;38(4):371-373.

11. Braun RM. Experimental peripheral nerve repair tubulation. Surg Forum. 1964;15:452-454.

12. Braun RM, Davidson K, Doehr S. Provocative testing in the diagnosis of dynamic carpal tunnel syndrome. $J$ Hand Surg [Am.]. 1989;14(2 Pt 1):195-197.

13. Brenner MJ, Jensen JN, Lowe JB III, et al. Anti-CD40 ligand antibody permits regeneration through peripheral nerve allografts in a nonhuman primate model. Plast Reconstr Surg. 2004;114(7):1802-1814.

14. Britz GW, Haynor DR, Kuntz C, et al. Ulnar nerve entrapment at the elbow: correlation of magnetic resonance imaging, clinical, electrodiagnostic, and intraoperative findings. Neurosurgery. 1996;38(3):458-465.

15. Brown DL, Bishop DK, Wood SY, Cederna PS. Shortterm anti-CD40 ligand costimulatory blockade induces tolerance to peripheral nerve allografts, resulting in improved skeletal muscle function. Plast Reconstr Surg. 2006;117(7):2250-2258.

16. Brown RA, Gelberman RH, Seiler JG. Carpal tunnel release. A prospective, randomized assessment of open and endoscopic methods. J Bone Joint Surg Am. 1993;75(9):1265-1275. 
17. Brunelli GA, Vigasio A, Brunelli GR. Different conduits in peripheral nerve surgery. Microsurgery. 1994;15(3): 176-178.

18. Burnett MG,Zager EL. Pathophysiology of peripheral nerve injury: a brief review. Neurosurg Focus. 2004;16(5):E1.

19. Catalano LW, Barron OA. Anterior subcutaneous transposition of the ulnar nerve. Hand Clin. 2007;23(3): 339-344, vi.

20. Chen CJ, Ou YC, Liao SL, et al. Transplantation of bone marrow stromal cells for peripheral nerve repair. Exp Neurol. 2007;204(1):443-453.

21. Coleman BG, Arger PH, Dalinka MK, Obringer AC, Raney BR, Meadows AT. CT of sarcomatous degeneration in neurofibromatosis. AJR Am J Roentgenol. 1983;140(2): 383-387.

22. Colin W, Donoff RB. Nerve regeneration through collagen tubes. J Dent Res. 1984;63(7):987-993.

23. Conley J, Baker DC. Hypoglossal-facial nerve anastomosis for reinnervation of the paralyzed face. Plast Reconstr Surg. 1979;63(1):63-72.

24. Cornwall R, Radomisli TE. Nerve injury in traumatic dislocation of the hip. Clin Orthop Relat Res. 2000;(377): 84-91.

25. Cruikshank W. Experiments on the nerves particularly on their reproductions; and the spinal marrow of living animals. Philos Trans R Soc Lond. 1795;85:177-189.

26. Crumley RL, Horn K, Clendenning D. Laryngeal reinnervation using the split-phrenic nerve-graft procedure. Otolaryngol Head Neck Surg. 1980;88(2):159-164.

27. Dalton PD, Flynn L, Shoichet MS. Manufacture of poly(2hydroxyethyl methacrylate-co-methyl methacrylate) hydrogel tubes for use as nerve guidance channels. Biomaterials. 2002;23(18):3843-3851.

28. Dellon AL, Hament W, Gittelshon A. Nonoperative management of cubital tunnel syndrome: an 8-year prospective study. Neurology. 1993;43(9):1673-1677.

29. Dellon AL, Mackinnon SE. Musculoaponeurotic variations along the course of the median nerve in the proximal forearm. J Hand Surg [Br.]. 1987;12(3):359-363.

30. Dellon AL, Mackinnon SE. Anatomic investigations of nerves at the wrist: II. Incidence of fibrous arch overlying motor branch of ulnar nerve. Ann Plast Surg. 1988;21(1): 36-37.

31. Ducatman BS, Scheithauer BW. Postirradiation neurofibrosarcoma. Cancer. 1983;51(6):1028-1033.

32. Eaton CJ, Lister GD. Radial nerve compression. Hand Clin. 1992;8(2):345-357.

33. Foley KM, Woodruff JM, Ellis FT, Posner JB. Radiationinduced malignant and atypical peripheral nerve sheath tumors. Ann Neurol. 1980;7(4):311-318.

34. Fujita I, Matsumoto K, Minami T, Kizaki T; Akisue T; Yamamoto T. Tarsal tunnel syndrome caused by epineural ganglion of the posterior tibial nerve: report of 2 cases and review of the literature. J Foot Ankle Surg. 2004;43(3): 185-190.

35. Fung BK, Chan KY, Lam LY, et al. Study of wrist posture, loading and repetitive motion as risk factors for developing carpal tunnel syndrome. Hand Surg. 2007;12(1):13-18.

36. Gerritsen AA, de Vet HC, Scholten RJ, Bertelsmann FW, de Krom MC, Bouter LM. Splinting vs surgery in the treatment of carpal tunnel syndrome: a randomized controlled trial. JAMA. 2002;288(10):1245-1251.

37. Gross MS, Gelberman RH. The anatomy of the distal ulnar tunnel. Clin Orthop Relat Res. 1985;(196):238-247.
38. Hall S. The response to injury in the peripheral nervous system. J Bone Joint Surg Br. 2005;87(10):1309-1319.

39. Heine W, Conant K, Griffin JW, Höke A. Transplanted neural stem cells promote axonal regeneration through chronically denervated peripheral nerves. Exp Neurol. 2004;189(2):231-240.

40. Hentz VR, Rosen JM, Xiao SJ, McGill KC, Abraham G. The nerve gap dilemma: a comparison of nerves repaired end to end under tension with nerve grafts in a primate model. J Hand Surg [Am.]. 1993;18(3):417-425.

41. Hess JR, Brenner MJ, Fox IK et al. Use of cold-preserved allografts seeded with autologous Schwann cells in the treatment of a long-gap peripheral nerve injury. Plast Reconstr Surg. 2007;119(1):246-259.

42. Hirose CB, McGarvey WC. Peripheral nerve entrapments. Foot Ankle Clin. 2004;9(2):255-269.

43. Horak E, Szentirmay Z, Sugar J. Pathologic features of nerve sheath tumors with respect to prognostic signs. Cancer. 1983;51(6):1159-1167.

44. Hudsonv TW, Liu SY, Schmidt CE. Engineering an improved acellular nerve graft via optimized chemical processing. Tissue Eng. 2004;10(9-10):1346-1358.

45. Itoh S, Suzuki M, Yamaguchi I et al. Development of a nerve scaffold using a tendon chitosan tube. Artif Organs. 2003;27(12):1079-1088.

46. Ivins GK. Meralgia paresthetica, the elusive diagnosis: clinical experience with 14 adult patients. Ann Surg. 2000;232(2):281-286.

47. Jensen JN, Tung TH, Mackinnon SE. Use of anti-CD40 ligand monoclonal antibody as antirejection therapy in a murine peripheral nerve allograft model. Microsurgery. 2004;24(4):309-315.

48. Keilhoff G, Pratsch F, Wolf G. Bridging extra large defects of peripheral nerves: possibilities and limitations of alternative biological grafts from acellular muscle and Schwann cells. Tissue Eng. 2005;11(7-8):1004-1014.

49. Kline DG, Hackett ER, Davis GD. Effect of mobilization on the blood supply and regeneration of injured nerves. $J$ Surg Res. 1972;12(4):254-266.

50. Kumar AJ, Kuhajda FP, Martinez CR. Computed tomography of extracranial nerve sheath tumors with pathological correlation. J Comput Assist Tomogr. 1983;7(5):857-865.

51. Lee SK, Wolfe SW. Peripheral nerve injury and repair. J Am Acad Orthop Surg. 2000;8(4):243-252.

52. Lotheissen G. Zur Technik der Nerven und Sehnennaht. Arch Klin Chir. 1901;34:310-313.

53. Lubahn JD, Cermak MB. Uncommon nerve compression syndromes of the upper extremity. J Am Acad Orthop Surg. 1998;6(6):378-386.

54. Lundborg G, Dahlin LB, Danielsen N. Nerve regeneration in silicone chambers: influence of gap length and of distal stump components. Exp Neurol. 1982;76(2):361-375.

55. Lundborg G, Rosen B, Dahlin L, Danielsen N, Holmberg J. Tubular versus conventional repair of median and ulnar nerves in the human forearm: early results from a prospective, randomized, clinical study. J Hand Surg [Am]. 1997; 22(1):99-106

56. Lundborg G, Rydevik B. Effects of stretching the tibial nerve of the rabbit. A preliminary study of the intraneural circulation and the barrier function of the perineurium. J Bone Joint Surg Br. 1973;55(2):390-401.

57. Mackinnon SE, Dellon AE. Nerve repair and nerve grafts. In: Surgery of the Peripheral Nerve. New York: Thieme Medical Publishers, 1988:89-129. 
58. Mackinnon SE. New directions in peripheral nerve surgery. Ann Plast Surg. 1989;22(3):257-273.

59. Mackinnon SE, Doolabh VB, Novak CB, Trulock EP. Clinical outcome following nerve allograft transplantation. Plast Reconstr Surg. 2001;107(6):1419-1429.

60. Mackinnon SE, Glickman LT, Dagum A. A technique for the treatment of neuroma in-continuity. J Reconstr Microsurg. 1992;8(5):379-383.

61. Macnicol MF, Thompson WJ. Idiopathic meralgia paresthetica. Clin Orthop Relat Res. 1990;254:270-274.

62. Mankin HJ, Hornicek FJ. Diagnosis, classification, and management of soft tissue sarcomas. Cancer Control. 2005;12(1):5-21.

63. Matsen FA, Mayo KA, Sheridan GW, Krugmire RB Jr. Monitoring of intramuscular pressure. Surgery. 1976;79(6):702-709.

64. McCallister WV, Cober SR, Norman A, Trumble TE. Using intact nerve to bridge peripheral nerve defects: an alternative to the use of nerve grafts. J Hand Surg [Am.]. 2001;26(2):315-325.

65. McQuarrie IG. Peripheral nerve surgery. Neurol Clin. 1985;3:(2), 453-466.

66. Midha R, Mackinnon SE, Becker LE. The fate of Schwann cells in peripheral nerve allografts. J Neuropathol Exp Neurol. 1994;53(3):316-322.

67. Millesi H, Meissl G, Berger A. Further experience with interfascicular grafting of the median, ulnar, and radial nerves. J Bone Joint Surg Am. 1976;58(2):209-218.

68. Mitra A, Stern JD, Perrotta VJ, Moyer RA. Peroneal nerve entrapment in athletes. Ann Plast Surg. 1995;35(4):366-368.

69. Mujadzic M, Papanicolaou G, Young H, Tsai T-M. Simultaneous surgical release of ipsilateral pronator teres and carpal tunnel syndromes. Plast Reconstr Surg. 2007;119(7):2141-2147.

70. Myckatyn TM, Mackinnon SE. Microsurgical Repair of Peripheral Nerves and Nerve Grafts. In: Thorne CH, ed. Grabb and Smith's Plastic Surgery. Wolters Kluwer: Lippincott Williams \& Wilkins; 2006:73-83.

71. Myckatyn TM, Mackinnon SE, McDonald JW. Stem cell transplantation and other novel techniques for promoting recovery from spinal cord injury. Transpl Immunol. 2004;12(3-4):343-358.

72. Nath RK, Mackinnon SE. Management of neuromas in the hand. Hand Clin. 1996;12(4):745-756.

73. Navarro X, Kennedy WR, Stewart NJ. Effects of laminin on functional reinnervation of target organs by regenerating axons. NeuroReport. 1991;2(1):37-40.

74. Novak CB, van VD, Mackinnon SE. Subjective outcome following surgical management of upper extremity neuromas. J Hand Surg [Am.]. 1995;20(2):221-226.

75. Osterman AL, Spiess AM. Medial epicondylectomy. Hand Clin. 2007;23(3):329-37, vi.

76. Paniello RC, West SE, Lee P. Laryngeal reinnervation with the hypoglossal nerve. I. Physiology, histochemistry, electromyography, and retrograde labeling in a canine model. Ann Otol Rhinol Laryngol. 2001;110(6):532-542.

77. Rodriguez FJ, Verdu E, Ceballos D. Nerve guides seeded with autologous schwann cells improve nerve regeneration. Exp Neurol. 2000;161(2):571-584.

78. Rosberg HE, Carlsson KS, Höjgård S, Lindgren B, Lundborg G, Dahlin LB. Injury to the human median and ulnar nerves in the forearm - analysis of costs for treatment and rehabilitation of 69 patients in southern Sweden. J Hand Surg [Br.]. 2005;30(1):35-39.
79. Rovak JM, Mungara AK, Aydin MA. Effects of vascular endothelial growth factor on nerve regeneration in acellular nerve grafts. J Reconstr Microsurg. 2004;20(1):53-58

80. Seddon HJ. Peripheral nerve injuries in Great Britain during World War II; a review. Arch Neurol Psychiatry. 1950;63(1):171-173

81. Sen SK, Lowe JB III, Brenner MJ, Hunter DA, Mackinnon SE. Assessment of the immune response to dose of nerve allografts. Plast Reconstr Surg. 2005;115(3):823-830.

82. Siemionow M, Tetik C, Ozer K, Ayhan S. Epineural sleeve neurorrhaphy: surgical technique and functional results - a preliminary report. Ann Plast Surg. 2002;48(3):281-285.

83. Snyder CC, Webster HD, Pickens JE. Intraneural neurorrhaphy: a preliminary clinical and histological evaluation. Ann Surg. 1968;167(5):691-696.

84. Spinner M, Spencer PS. Nerve compression lesions of the upper extremity. A clinical and experimental review. Clin Orthop Relat Res. 1974;(104):46-67.

85. Spinner RJ, Amadio PC. Compressive neuropathies of the upper extremity. Clin Plast Surg. 2003;30(2):155-73, vi.

86. Strauch B. Use of nerve conduits in peripheral nerve repair. Hand Clin. 2000;16:(1), 123-130.

87. Sunderland S. Nerve Injuries and Their Repair: A Critical Appraisal. New York: Churchill Livingstone; 1991: 467-497.

88. Takahashi M, Satou T, Hashimoto S. Experimental in vivo regeneration of peripheral nerve axons and perineurium guided by resorbable collagen film. Acta Pathol Jpn. 1988;38(12):1489-1502.

89. Tetik C, Ozer K, Ayhan S, Siemionow K, Browne E, Siemionow M. Conventional versus epineural sleeve neurorrhaphy technique: functional and histomorphometric analysis. Ann Plast Surg. 2002;49(4):397-403.

90. Thoma A, Fawcett S, Ginty M,Veltri K. Decompression of the common peroneal nerve: experience with 20 consecutive cases. Plast Reconstr Surg. 2001;107(5) 1183-1189.

91. Thoma A, Levis C. Compression neuropathies of the lower extremity. Clin Plast Surg. 2003;30(2):189-201, vi.

92. Thomas JE, Piepgras DG, Scheithauer B. Neurogenic tumors of the sciatic nerve. A clinicopathologic study of 35 cases. Mayo Clin Proc. 1983;58:(10), 640-647.

93. Townsend PL. Microsurgical techniques in reconstructive surgery. In: Keen G, Farndon JR, eds. 1994:434-435.

94. Trumble TE. Peripheral nerve injury: pathophysiology and repair. In: Feliciano DV, Moore EE, Mattox KL, eds. 1999:2048-2053

95. Trumble TE, Diao E, Abrams RA. Single-portal endoscopic carpal tunnel release compared with open release: a prospective, randomized trial. J Bone Joint Surg Am. 2002;84-A:(7), 1107-1115.

96. Trumble TE, Shon FG. The physiology of nerve transplantation. Hand Clin. 2000;16(1):105-122.

97. Vernadakis AJ, Koch H, Mackinnon SE. Management of neuromas. Clin Plast Surg. 2003;30(2):247-68, vii.

98. Waugh RP, Pellegrini VD. Ulnar tunnel syndrome. Hand Clin. 2007;23(3):301-10, v.

99. Weber RA, Breidenbach WC, Brown RE, Jabaley ME, Mass DP. A randomized prospective study of polyglycolic acid conduits for digital nerve reconstruction in humans. Plast Reconstr Surg. 2000;106(5):1036-1045.

100. Weiss P, Taylor AC. Guides for nerve regeneration across gaps. J Neurosurg. 1946;3:375-389. 
101. Widmer MS, Gupta PK, Lu L. Manufacture of porous biodegradable polymer conduits by an extrusion process for guided tissue regeneration. Biomaterials. 1998;19(21): 1945-1955.

102. Yamaguchi I, Itoh S, Suzuki M, Sakane M, Osaka A, Tanaka J. The chitosan prepared from crab tendon I: the characterization and the mechanical properties. Biomaterials. 2003;24(12):2031-2036.

103. Younwwg RC, Wiberg M, Terenghi G. Poly-3hydroxybutyrate (PHB): a resorbable conduit for long- gap repair in peripheral nerves. Br J Plast Surg. 2002;55(3):235-240.

104. Zhang P, He X, Zhao F. Bridging small-gap peripheral nerve defects using biodegradable chitin conduits with cultured schwann and bone marrow stromal cells in rats. J Reconstr Microsurg. 2005; 21(8): 565-571.

105. Zhasng L, Chen ZW, Haung SR. Experimental study of regeneration of motor end plate. Microsurgery. 1986;7(4):148-150. 